\title{
Sharing system of learning resources for adaptive strategies of scholastic remedial intervention
}

\author{
Barana, Alice ${ }^{a}$; Di Caro, Luigi ${ }^{b}$; Fioravera, Michele ${ }^{a}$; Floris, Francesco ${ }^{a}$; Marchisio, \\ Marina $^{a}$ and Rabellino, Sergio ${ }^{b}$ \\ ${ }^{\mathrm{a}}$ Department of Mathematics, University of Turin, Italy ${ }^{\mathrm{b}}$ Department of Computer Science, \\ University of Turin, Italy.
}

\begin{abstract}
This paper presents a model for school remedial, focusing on improving the digital materials sharing process for the diversification of tutoring strategies. The model involves the characterization of materials for automatic assessment shared within a community of tutors. The characterization expects materials to be linked with natural language descriptors explicating their intended instructional objectives. The possibility of implementing a recommendation system on the basis of natural language processing techniques is discussed taking in consideration an analysis of the application of the model within a local-scale project. Clustering techniques searching for materials that have the same educational purposes but involve the activation of different cognitive processes are proposed, in order to continuously extend the database of shared materials in favour of the effectiveness of ongoing tutoring actions. The results collected from questionnaires submitted to students, tutors, and teachers involved in the project are shown, and clustering data are discussed highlighting the feasibility of the application of the model.
\end{abstract}

Keywords: Adaptive tutoring; automatic assessment; clustering; sharing; virtual learning environment. 


\section{Introduction}

The success of adaptive tutoring requires an accurate diagnosis of learners' needs. Technology Enhanced Learning Environments (TELEs) enable the creation of communities of practice dedicated to tutoring interventions based on digital technology, where sharing can enhance a diversification of contents in favour of different learners. In this process, the collection of explicit descriptions of learning intentions can be used as the basis for the recognition of optimal content. In this paper, automated recommendation of learning materials is proposed considering prerequisites and learning objective specified as metadata of resources for automatic assessment.

The present research discusses the design of materials created within a project for school remedial in mathematics. Clustering analysis is proposed to search for resources produced in previous editions and recommended for ongoing interventions, considering the specific necessities. Results from different editions of the project are presented. They show the effectiveness of experimental actions of school remedial, conducted using advanced tools integrated with a Virtual Learning Environment (VLE), on the basis of problem posing and solving methodology. A system for sharing digital resources among tutors is proposed to enhance the efficiency of the remedial interventions explicated through specific descriptors.

\section{State of the art}

The idea of technology-based adaptive teaching (Snow 1977) was born from the interest in individual differences among learners, who might show different attitudes toward learning and respond to different forms of instructions in different ways (Jonassen \& Grabowski 1993), possibly changing over time. Instructional strategies should be adjusted accordingly with the student's progresses (Jonassen et al. 1990), which need to be continuously controlled. To enable an automated monitoring of learning outcomes, several online systems have been developed. According to the collection of assessment data, analysis of activities and feedback, the design of personalized paths can be constructed with materials and activities which best meet the students’ needs (Shute \& Zapata-Rivera 2007).

The use of ICTs boost the positive effects that the use of adaptive teaching methodologies has on the learners (Phobun \& Vicheanpanya 2010): lessons are engaging, relevant, and interesting; the learning environment is comfortable and learners feel at ease; learners do not worry about saying something wrong, in fact mistakes are necessary to inform the teacher about how to adjust the strategy; learners take increasing responsibility for their own growth (Tomlision 2001). These factors are particularly relevant in contexts of tutoring as key points for the promotion of school success (Mascarenhas et al. 2011). 
The project presented in this paper has been subject of study in few research on the positive effects of peer tutoring in fostering the student motivation (Ricchiardi \& Torre 2014). The methodologies of the experimental Mathematics part of the project follow the same trend indicated by the Italian Ministry of Education and applied in the national project Problem Posing and Solving (Brancaccio et al. 2014). They have also been adopted within the Erasmus+ Project SMART (Science and Mathematics Advanced Research for good Teaching) (Brancaccio et al. 2016). In this paper, the tutoring process of the project is analyzed in the perspective of Instructional Design (ID). ID is a technology for the development of learning experiences and environments which promote the acquisition of specific knowledge and skill by students, incorporating learning strategies which make the acquisition of knowledge and skill more efficient, effective, and appealing.

\section{The project}

The project "Scuola dei compiti” (“School of Homework") aims at reducing scholastic failures. It offers remedial actions through tutoring activities supported by new technologies and innovative educational methodologies developed by the University of Turin (Cavagnero et al. 2015). The project started in the school year 2012/2013, as a collaboration between the University, the Polytechnic, the City of Turin and the association of retired teachers. Twenty schools, divided between secondary schools of first and second grade, have taken part in the project, now in its seventh edition currently underway. The targeted action for the recovery of unsuccessful situations is directed to the students in the transition phase between the two school levels, through afternoon courses and online activities on courses hosted on a Moodle VLE. Tutoring is held by undergraduates of the University of Turin or the Polytechnic of Turin. The VLE is integrated with an Advanced Computing Environment (ACE), an Automatic Assessment System (AAS) and a web conference tool.

The tutoring activity is organized on a weekly basis as follows:

- two hours of meeting in presence

- $\quad$ one hour of distance learning using the web-conference tool

Tutors are asked to prepare new materials according to the specific needs diagnosticated to the learners. To help them create and diversify the materials, resources produced in previous editions of the project have been made available to inspire the creation of new materials. 


\section{Automatic Assessment}

The project strongly relies on the adoption of the suite of software integrated to the VLE. The Automatic Assessment System (Maple TA) allows students to practice wherever and whenever they want and to receive immediate feedback on their level of preparation with indications on the educational material to be reviewed on the basis of the results obtained. The Moodle gradebook is integrated with Maple TA, so that it is possible to monitor student progresses and to find out their difficulties. One of the many potentialities of the software are the adaptive questions: they allow students to submit real-life problems, leaving more space to the reasoning process and giving them more attempts to find a solution. In case of failure, a guided path towards the solution is proposed, dividing the proposed problem into successive steps that guide the student's reasoning (Barana et al. 2015).

\section{Methodology}

The tutoring action can be analysed with the 5 phases that characterize the ADDIE model (Analyse, Design, Develop, Implement and Evaluate) of Instructional Design. The 5 phases, which alternate cyclically during the various weeks in which the support and recovery actions develop, can be described as follows:

- Analyse. Needs analysis takes place in the first phase of the project and in itinere: needs are firstly agreed with the teachers in service of the students who take part in the afternoon courses. Tutors investigate students' achievements on a weekly basis and develop the interventions accordingly.

- Design. The explication of specific learning objectives must be consistent with the needs analysis phase. Simultaneously the tutor is required to identify the prerequisites that the student must meet in order to reach the learning objectives.

- Develop. The strong versatility of the ACE and the AAS enables the creation of a wide range of different interactive materials to be offered to the students, in line with the criteria defined in the Design phase.

- Implement. Activities are submitted both in presence to the students and made available via the VLE.

- Evaluate. Tutors assess whether the proposed activities have allowed the students to reach the pre-established learning objectives. The specification of the couple (objectives, prerequisites) is crucial for determining where to intervene next. 


\subsection{Authoring and sharing materials for automatic assessment}

It is proposed to associate digital materials to natural language descriptions which explicate the learning intentions and success criteria they were designed for. The model provides for a pair of descriptors (objectives, prerequisites), defined as follows, to be included as metadata:

- Objectives (or "goals") specifies what learners are required to be able to do as a result of the learning activity related to the MLO. This statement should not simply describe a list of topics, that being too abstract, too narrow, nor being restricted to lower-level cognitive skills.

- Requisites (or “prerequisites”) states the tutor's belief of the necessary and sufficient condition to attempt performing the learning material. It is the explicit declaration of previous knowledge and skills necessary and sufficient to achieve the Objectives.

The two descriptors must be expressed in a student-centred manner.

Figure 1 shows an example learning material.

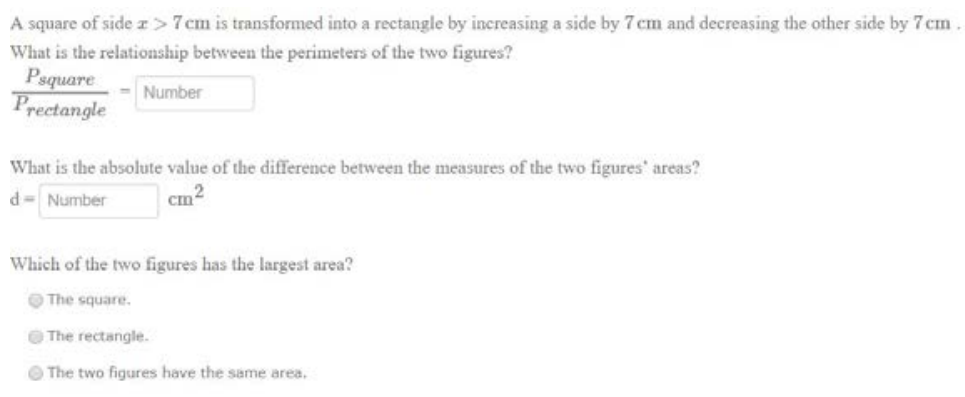

Figure 1. Example of learning material for automatic assessment.

One example of Requisites of the learning material of Figure 1 would be "Knowing the concept of perimeter and how to calculate it for squares and rectangles". An example of Objectives would be: “Comparing polygons by the calculus of areas”.

Materials sharing interacts with the three central phases of the ADDIE model (Design, Develop and Implement): in the design phase, tutors are fostered to think more deeply about the objectives and prerequisites. In the development and implementation phases, they could find new ideas drawn from diversified material. 


\subsection{Clustering learning materials}

Descriptors express which student's performance is required in terms of activated cognitive processes and types of knowledge on which these processes operate. To this aim, the adoption of a taxonomic reference is proposed: Anderson \& Krathwohl's taxonomy (Anderson et al. 2001). Anderson \& Krathwohl proposed a classification of cognitive processes and knowledge types: 11 types of knowledge organized into 4 categories (Facts, Concepts, Procedures, Metacognition), and 19 basic processes organized into 6 categories (Remember, Understand, Apply, Analyse, Evaluate, Create) ordered by ascending cognitive complexity.

Considering Anderson \& Krathwohl's taxonomy, learning materials can be linked to a set of concepts' couples referring to a $4 \times 6$ matrix: the first dimension of the matrix represents the types of knowledge while the second dimension represents the cognitive processes involved. The connection between a material and a matrix's element is established by identifying cognitive processes and knowledge type from clues in content or metadata, such as

- $\quad$ one or more 'action verbs', each being a synonym of a single cognitive process;

- $\quad$ one or more disciplinary terms, each related to a single knowledge concept;

As an example, the Objective of Figure 1 "Comparing polygons by the calculus of areas" would be linked to the cognitive process from the category Understand because of the presence of the verb "Comparing”. As illustrated in Figure 2, the presence of an action verb (leaf element) is considered as an indicator of a cognitive process.

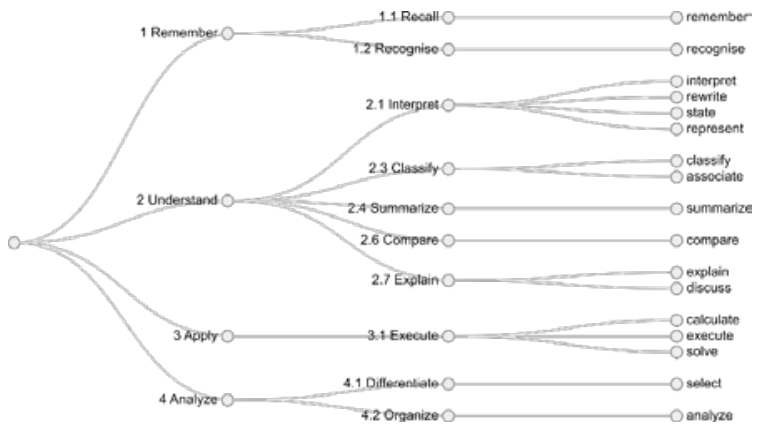

Figure 2. Example action verbs and related cognitive processes as defined by Anderson \& Krathwohl's taxonomy.

Similarly, the presence of disciplinary contents (leaves) indicate knowledge types. To actually detect the cues in descriptors, an ontological version of Anderson \& Krathwohl taxonomy integrated with the domain-specific OntoMath ${ }^{\mathrm{PRO}}$ ontology is proposed (Nevzorova et al. 2014). OntoMath ${ }^{\text {PRO }}$ is a bilingual (Russian/English) ontology of mathematical knowledge, geared to be the hub for Math knowledge on the Web of Data. 
Sources shared by the developers with the Semantic Web community are translated in Italian.

\section{Results and discussion}

The following results are obtained by analysing the questionnaires proposed at the end of the previous editions of the project and submitted to the three subjects involved in the project for mathematics: tutors, students and teachers in service. A questionnaire asks tutors to evaluate their consideration on the importance of using the VLE, the ACE, the AAS, and all those tools integrated for adaptive tutoring (Barana et al. 2017), in a Likert scale from 1 to 5 . Table 1 shows questionnaire results, which highlight the importance of the use of the AAS and all the technological tools integrated.

Table 1. Tutors' responses to the importance of the tool for adaptive tutoring.

\begin{tabular}{lcccl}
\hline & VLE & ACE & AAS & integration \\
\hline Average & 3.6 & 3.7 & 4.9 & 4.6 \\
Standard deviation & 1.0 & 1.1 & 0.9 & 0.6 \\
\hline
\end{tabular}

To evaluate the effectiveness and attractiveness of the project, students' answers were analyzed and the improvement between the initial and final phase of the project in terms of school media was recorded. There is an increase in average of about 0.73 points, which increases to 0.78 considering only students who regularly attend the afternoon courses and actively participate in the activities proposed by the tutors. On the basis of the teachers' opinion, the course has been useful for $80 \%$ of students who attended mathematics course and these values increase with the students' attendance to the courses.

Table 2 shows the mean and standard deviation of the answers of the students' questionnaire regarding their appreciation of the various activities proposed on the platform. As it can be seen, also in this case the AAS has an average of 3.62 (standard deviation 1.015) and a good part of students, in addition to recognizing the effectiveness of the proposed tools, would like the methodologies based on digital tools to be introduced in the regular school lessons. 
Table 2. Students' responses to the questionnaire.

\begin{tabular}{ccc}
\hline Question & Mean & Std dev \\
\hline $\begin{array}{c}\text { How much did you appreciate being able to perform exercises and checks } \\
\text { on the computer with automatic correction? }\end{array}$ & 3.62 & 1.015 \\
Were the materials interesting? & 3.628 & 0.87 \\
$\begin{array}{c}\text { Do you think these platform resources have helped you improve? } \\
\text { regular school lessons? }\end{array}$ & 3.00 & 1.23 \\
$\begin{array}{c}\text { Would you like to have a platform and be able to use the computer even in } \\
\text { How much did you appreciate the availability of material on the platform? }\end{array}$ & 3.84 & 1.15 \\
& & 0.90 \\
\hline
\end{tabular}

\section{Conclusion}

The evaluation made by the subjects involved suggests the effectiveness and attractiveness of the project. A more efficient sharing system allows an ongoing monitoring of the quality of the project. A comparison between the descriptors inserted by different tutors allows analysing different strategies adopted on the basis of a common methodology, that will be helpful for assessing the project's outcomes.

\section{References}

Anderson, L. W., Krathwohl, D. R. et al. (2001). A taxonomy for learning, teaching, and assessing. A revision of Bloom's taxonomy of educational objectives. New York, Addison Wesley Longman.

Barana, A., Marchisio, M., Rabellino, S. (2015). Automated assessment in mathematics. Proceedings - International Computer Software and Applications Conference. pp. 670671.

Barana, A., Fioravera, M., Marchisio, M., Rabellino, S. (2107). Adaptive Teaching Supported by ICTs to Reduce the School Failure in the Project 'Scuola Dei Compiti'. Proceedings - International Computer Software and Applications Conference, pp. 432437.

Brancaccio, A., Demartini, C.G., Marchisio, M., Pardini, C., Patrucco, A. (2014). Il progetto PP\&S informatica a scuola. Mondo Digitale 13(51), pp. 565-574.

Brancaccio, A., Esposito, M., Marchisio, M., Pardini, C. (2016). L'efficacia dell'apprendimento in rete degli immigrati digitali. L'esperienza SMART per le discipline scientifiche. Mondo Digitale 15(64), pp. 803-821. 
Cavagnero, S.M., Gallina, M.A., Marchisio, M. (2015). Scuola dei compiti. Didattica digitale per il recupero dell'insuccesso scolastico. Mondo Digitale 14(58), pp. 834-843.

Jonassen, D. H., Grabowski, B. L. (1993). Hanbook of Individual Differences, Learning and Instruction. Hillsdale, New Jersey: Laurence Erlbaum Associates, Publishers.

Jonassen, D. H., Grabinger, R. S., Harris, N. D. C. (1990). Analyzing and Selecting Instructional Strategies and Tactics. Performance Improvement Quarterly, vol. 3, n. 2.

Mascarenhas, A., Parson, S., Cohen Burrowbridge S. (2011). Preparing Teachers for HighNeed Schools: A Focus on Thoughtfully Adaptive Teaching. Occasional Paper Series, vol. 2011, n. 25.

Nevzorova, O., Zhiltsov, N., Nikita, Kirillovich, A., Lipachev, E. (2014). OntoMathPRO ontology: A linked data hub for mathematics. Communications in Computer and Information Science, vol. 468, pages 105-119.

Phobun P., Vicheanpanya, J. (2010). Adaptive intelligent tutoring systems for e-learning systems. Procedia - Social and Behavioral Sciences, vol. 2, n. 2.

Ricchiardi, P., Torre, E. M. T. (2014). Progetti di tutoring per contrastare l'insuccesso scolastico e favorire la motivazione ad apprendere nella scuola secondaria. L'integrazione scolastica e sociale, vol. 13, n. 3, pp. 285-306.

Shute, V. J., Zapata-Rivera, D. (2007). Adaptive Technologies. Educational Testing Service, Princeton.

Snow, R. E. (1977). Individual Differences and Instructional Theory. Educational Researcher, vol. 6, pp. 11-16.

Tomlision, C. A. (2001). How to Differentiate Instruction in Mixed-Ability Classrooms. Alexandria, VA: ASCD.

Wang F., Hannafin, M. J. (2005). Design-Based Research and Technology-Enhanced Learning Environments. Educational Technology Research and Development, Vol. 53, No. 4 (2005), pp. 5-23. 